\title{
XXIII. On the benzoic acid in the urine of horses
}

\section{Ferdinand Giese}

To cite this article: M. Ferdinand Giese (1803) XXIII. On the benzoic acid in the urine of horses , Philosophical Magazine Series 1, 17:66, 151-156, DOI: 10.1080/14786440308676388

To link to this article: http://dx.doi.org/10.1080/14786440308676388

$$
\text { 曲 Published online: } 18 \text { May } 2009 .
$$

Submit your article to this journal

LII Article views: 2

Q View related articles $\asymp$ 
pound of pot or pearl ashes; pour the clear lye into the boiling-pan; add a sufficient quantity of . water thercto that will cover the yarn about four inches; light the fire, and enter the yarn, when the liquor is a little warm; observe to keep it constantly under the liquor for two huurs; in: crease the heat regularly till it cone to a scald; then take the yarn out, wash it, and hang it to dry as in former operations.

\section{Seventh Operation.}

Make a sour liquor of oil of vitriol and water; the degree of acidity may be a little less than the juice of lemons; lay the yarn in it for about an hour, then take it out, wash it very well and wring it; give it a second washing and wiringing, and lay it on a board.

N.B. This operation is to dissolve the metallic particles, and remove the ferruginous matter that remains on the surface of the thread after the fifth opertion.

\section{Eighth Operation.}

For every ten pounds of yarn dissolve one pound of best white soap in clear water, and add as much water to this liquor in your boiling-pan as will be sufficient to boil the yarn for two hours. When these liquors are well mixed light the fire, enter the yarn, and bring the liquor to boil in about an hour. Continue it boiling slowly an hour; take it out, wash it in clear water very well, and hang it to dry as in former operations: when dry it is ready for the weaver.

N. B. It appears to me, from experiments that I have made, that less than four operations in the preparation of the yarn will not be sufficient to cleanse the pores of the fibres of the cotton, and render the colour permanent.

XXIII. On the Benzoic Acid in the Lrine of Horses. By $M$. Ferdinand Giese, of Berlin *.

Acconding to the researches of Fourcroy and Vauquelin on the urine of different graminivorons animals, the benzoic acid at all times forms a component part of it. Partly with a view to place this beyond a doubt, and partly that I might accurately determine the proportion which this substance bears to the other component parts, I made the following

- From Scherer's Allgemeines Yournal der Chemie, no. 41.

K 4

experi- 


\section{On the Benzoic Acid in the Urine of Horses.}

experiments; but these conducted me to phænomena which induced me to proceed further than I had at first purposed.

\section{Experiment I.}

To two pounds of fresh horse's urine I added muriatic acid the specific gravity of which was as 115 to 100. A weak effervescence took place, and there were formed thick white vapours, which soon fell to the bottom like fakes. I now continued to add muriatic acid till nothing more was separated, and till there remained a small excess, three ounces of acid having been employed. The whole was then placed on a filter; and the precipitate, being washed with pure water to free it from the urine still adhering to it, was then dried. It amounted in weight to tira drams and forty-eight grains. On being subjected to a proper test, it evidently exhibited all the properties by which the benzoic acid is characterized; namely, a scarcely sourjsh taste, crystallization, complete volatility, the disengagement of an acrid vapour, which occasioned pain in the breast, and ready solution in spirit of wine.

Having filly convinced myself by this experiment of the abundant existence of benzoic acid in urine, I continued my researches on the urine of more horses, partly with a view of observing the difference of the proportions in it; and partly to ascertain whether something determinate might not be established on this subject.

\section{Experiment II,}

Four pounds of urine were subjected to the same treatment as before. 'The phrenomena were here different from those of the first experiment; for, on adding muriatic acid, to precipitate was produced. When the fluid was evaporated to a fourth, and after the fluid had stiood at rest for some time, I observed a small and resin-like precipitate, which, after being treated with spirit of wine, gave benzoic acid, but in so small a quantity that it bore no proportion to that of the first experimient, for it amounted only to five grains.

\section{Experiment III.}

Eight pounds of horsc's urine being eraporated to the consistence of syrup, muriatic acid was then added; but no precipitation ensued. The fluid was then brought to complete dryness' and spirit of 'wine being pdured over it, when it had stood some time the undissolved residuum was separated by the filter, and the liquor evaporated. I obtained a very small quantity of crystallized benzoic acid, which, 
which, as none appeared by pouring muriatic acid into the urine evaporated to the consistence of isyrup, must have existed in the urine in a free state. The weight of it amounted to fifteen grains..

\section{Experiment IV.}

Five pounds of urine were evaporated to dryness, and a fourth part of alcohol being added, the whole was exposed to heat. The alcohol, which after some time had acquired a dark colour, was again filtered and evaporated. No traces of benzoic acid, however, were perceptible.

\section{Experiment V.}

Of four pqunds of urine a swall part was subjected to previous proof by muriatic acid: a nebulous precipitate immediately took place, but on the addition of more muriatic acid it again disappeared. The remaining urine not decumposed with muriatic acid I evaporated to the consistence of syrup, by which means a great quantity of pure calcareous earth was separated ; to the discovery of which $I$ was conducted by dissolving the residuum in muriatic acid, which was very easily done, and without effervescence. Having dropped sulphuric acid into this solution," sulphate of lime was immediately formed." The urine separated from the calcareous earth was decomposed by sulphuric acid: there was formed a perceptible precipitate, which being digested with alcohol had lost none of its weight, and which was merely sulphate of lime." The precipitate then, first producef in the unevaporated curine by müriatic acid, did not by any means arise from benzoic acid.

It appears from these experiments, that in consequence of the great difference observed in them it is not possible to determine the proportions of the component parts of the urine,

In the many experiments which I made with the urine of different horses, I always found deviations in those which contanied benzoic acid. In general, I found none of this acid ; in some cases', but very seldom, 'I found a considerable quantity of it ; calcareous earth I found only once.

Whence then arises this great difference? The answer to this question will, perhaps, inake us better acquainted with the cause of these differences, "To accomplish this end, it was, in the first place, necessary to examine into the origin of this acid, whether it was formed "froin the vegetables on which the horses fed, and conveyed into the urine, or whether it was created in the animal body by the mutual 


\section{On the Benzoic Acid in the Urine of Horses.}

action of its original elements. I therefore first undertook to examine the usual food of these animals, hay and oats. Hay contains a large quantity, of a grass with a very agrceable smell, the anthoxantlum odoratum Linn. Fourcroy and Vauquelin had already suspected that this plant contained benzoic acid: this and other considerations confirmed me in the same opinion, and gave me reason to hope that I should find in it the source of the benzoic acid.

\section{Experiment I.}

A quantity of this grass was put into a very dry retort connected with a balneum maria, and, being placed in a sand-bath, was exposed to such a degree of heat that the benzoic acid contained in it could be sublimated; but after the fire had been maintained a considerable time, no traces of it were observed.

\section{Experiment II,}

One part of this grass was boiled with twelve parts of lime water. The decoction had a very agreeable smell : it was then brought to the consistence of syrup; and muriatic acid being added, a precipitate was produced, which however on being tried exhibited none of the properties of benzoic acid.

\section{Experiment III,}

An extract prepared from a quantity of this grass had a very strong smell, very much like that of the trifolium me lilotum. This extract, being digested some time in spirit of wine, had a very agreeable smell. It was then exposed to a slow evaporation, after which it exhibited no perceptible traces of benzoic acid.

It results from these experiments, made in different ways, that the benzoic acid does not originate from the hay.

It now remained for me to examine oats: I therefore subjected it to the same process, but could discover no signs of benzoic acid.

Being confident that I had pursued the right method in these experiments, I thought myself authorized to conclude with certainty that I must look for the origin of the benzoic acid in the animal body itself. The following experiments will serve as a confirmation of this idea :

I examined the urine of a horse which had been fed on the same food as that given to those the urine of which produced a large quantity of benzoic acid. This urine, however, produced very little. Had the benzoic acid been indebted for its origin to the food, the urine of horses fed 
an the same, fodder must have produced a like quantity of henzoic acid; which, after repeated experiments, was not found to be the case. A question now arises, In what state of the animal is this acid formed in the body? in the sound or diseased state? I flatter myself that $I$ am able to answer this question, as I had an opportunity of ascertaining, with great correctness, the state of the horses the urine of which 1 examined, The result was, that a horse whose urine gave a great deal of benzoic acid had been long diseased, and that the horse whose urine gave very little or no benzoic acid was perfectly sound. But what is the disease during which benzoic acid is produced? This question is the most important and most difficult. The determination of it is of great importance to the physiologist, as it calls his attention towards the cause of the formation of this acid; and is worthy the notice of the chemist also, as it holds forth an inducement for him to examine under what circumstances he can derive utility from this product.

For this purpose a long series of experiments would be necessary; but these experiments can be made only by those who have the care of diseased horses, that is to say, in a veterinary college. Hitherto I have had no opportunity of undertaking this labour; I shall therefore content myself with collecting into one point of view the facts which seem to result from these experiments.

I. The urine of borses is so very different, that nothing pertain can be determined in regard to the quantity of benzoic acid which it contains.

II. The following five cases, however, occur in this respect in the preceding experiments :-1st, There are some kinds of urine in which at first a large quantity of benzoic acid is found neutralized with soda: od, In which a very small quantity of benzoate of soda exists : $3 \mathrm{~d}$, In which the same quantity is found in the free state: 4 th, In which none is to be found : and, 5th, In which only a large quantity of pure calcareous earth is observed,

III. The difference of urine in regard to the benzoic acid it contains, does not arise from the food of the horses, but from the various states in which these animals may be by derangements in their functions.

IV. The state of the animal in which a quantity of benzoic acid is produced, is worthy of further examination.

\section{Remark by M. Scherer.}

It is always very difficult in researches of this kind to obtain certain results, I think there is great reason to be- 


\section{On some Properties of the Phosphoric Acid}

lieve that benzoic acid is to be found in the urine of every sound horse 3 but the principal point is the time when it voided. It is well known that in the urina cruda of man very little ure found; nay, it often seems to be entirely wanting. On the other hand, it is always found in the arina cocta of persons wbo are in a sound condition. May not the case be the samewith animals? Is it not therefore more than probable that the concocted urine of sound horses always contains benzoic acid," when no trace of it is to be found in the crude urine of the same animals? This difference is of so much importance that it ought not to be entirely overlooked.

XXIV. On some Properties of the Phosphoric Acid not yet sufficiently known. By M.J.F. Guersen, Apothecary of Kiel *.

\section{Susceptibility of crystallization.}

Tus property which the phosphoric acid possesses of being transformed into a vitreous mass by exposure to heat, was. one of its characteristic signs first known: this was not the case, however, with its suoceptibility of crystallization. It is not improbable that the method long employed of obtaining it from urine and bones, and the continued fusion of it to free it from the sulphurous acid, may have prevented chemists from knowing it in that state of concentration in which it shoots into crystals.

De Lassonne and Cornettet, however, speak of a phosphoric acid which was in the ratio of 19:8 to water, and which being mixed in the proportion of two parts to one part of water, formed after cooling a gelatinous kind of mass. This phænomenon, however, while the phosphoric acid was so much diluted, seems to have arisen rather from a mixture of earthy matter than from the property of the acid to crystallize.

Guttling $f$ is undoubtedly the first chemist who observed this property of the phosphoric acid, which he did accidentally, on having suffered phosphorus to stand for three months in a cellar in a glass filled with carbonic acid: at the end of this period he faund the sides of the glass $\mathrm{CO}_{\text {- }}$

* From Scherer's Allgemeines Fournal der Cbemie, no. 44 .

+ Mem, de l'Acad. de Paris, 1780 ; and Crell's Chem. Annals, 1786, vul. ii.

$\ddagger$ Göttling:s Tascherbuch fur das jahr, 1797. 